\title{
Integração dos elementos tempo/espaço e aprendizagem no cotidiano da sala de aula
}

\author{
Time/space integration and learning \\ at daily classroom contexts
}

\section{Evelise Maria Labatut Portilho[al, Liliamar Hoça ${ }^{[b]}$}

[a] Professora Doutora da Pontifícia Universidade Católica do Paraná (PUCPR), coordenadora da pesquisa Aprendizagem e Conhecimento na Ação Educativa, Curitiba, PR - Brasil, e-mail: evelisep@onda.com.br

[b] Professora Mestre da Universidade Positivo, pedagoga da Prefeitura Municipal de Curitiba, Curitiba, PR - Brasil, e-mail: liliamarh@brturbo.com.br

\section{Resumo}

O ensino organizado em ciclos pressupõe modificações no tempo/ espaço escolar em função do processo de aprendizagem das crianças. Este trabalho apresenta os procedimentos utilizados pelos educadores em escolas organizadas em ciclos, com relação à integração tempo/ espaço e aprendizagem no cotidiano da sala de aula, a partir da pesquisa realizada em escolas com o ensino organizado em ciclos. É uma pesquisa de abordagem qualitativa, na qual se realizaram entrevistas com 11 profissionais, sendo quatro pedagogas e sete professoras da $1^{\mathrm{a}}$ etapa 
do Ciclo I, de duas escolas públicas da cidade de Curitiba. Foi possível observar que os procedimentos utilizados pelos educadores, tanto em sala de aula como fora dela, são atividades pontuais e partem das dificuldades em relação ao processo de aprendizagem dos alunos que as professoras observam. As colocações realizadas pelas profissionais e a literatura consultada demonstram que as discussões sobre a concepção de ciclo e a questão do tempo/espaço escolar como período de formação e a aprendizagem necessitam ser retomadas para que se alcance o objetivo da formação integral dos alunos.

Palavras-chave: Tempo. Espaço. Aprendizagem. Ensino em ciclos.

\section{Abstract}

Cycle-organized teaching requires changings in school time/space regarding children's learning process. This work presents procedures that have been used by teachers at schools that have adopted the cicleorganized teaching, related to time/space integration and learning at day by day classroom contexts, from a research accomplished at cicle-organized teaching schools. It's a qualitative approached research in which 11 professionals were interviewed, four pedagogues and seven school teachers of Cicle I first stage of two public schools in the city of Curitiba. It was possible to observe that the procedures utilized by teachers, in class or out of classroom context, are punctual activities and derive from difficulties presented by students that are observed by teachers. Statements made by professionals and literature overviewed demonstrate that discussions about the concept of cicles and the question about school time/space as a period of education and learning need to be rescued in order to achieve the purpose of an integral education.

Keywords: Time. Space. Learning. Teaching in cicles. 


\section{Introdução}

A organização doensino em ciclos éuma proposta presente em muitos municípios brasileiros, que visa à reformulação dos programas escolares, à organização das classes, à concepção de ensino/aprendizagem, e aos processos avaliativos, possibilitando a ressignificação do tempo/espaço na escola.

O ensino em ciclos concebe a escola como tempo/espaço de formação, em compromisso com o desenvolvimento integral dos alunos, considerando as suas trajetórias de vida, os conhecimentos construídos histórico e culturalmente, a apropriação dos instrumentos de mediação e também as vivências e saberes dos professores.

Este trabalho corresponde a uma parte dos dados da pesquisa realizada no Mestrado em Educação da PUCPR, em escolas municipais da cidade de Curitiba, sobre os elementos tempo/espaço na prática dos docentes que atuam em escolas com ensino organizado em ciclos.

O objetivo desta investigação foi identificar na proposta de organização do ensino em ciclos os procedimentos utilizados na escola pelos educadores com relação à integração tempo/espaço em sala de aula.

A pesquisa foi realizada em duas escolas municipais, com 11 profissionais, sete professoras da $1^{a}$ etapa do Ciclo I e quatro pedagogas. Foram realizadas entrevistas para coleta de dados que revelassem se em função do processo de aprendizagem dos alunos foi proposta alguma forma de organização, levando em consideração os elementos tempo/espaço.

No período de implantação e decorrente implementaçãodos Ciclos de Aprendizagem, muitos documentos foram consultados e foi possível constatar que traziam em comum as reflexões sobre a singularidade do processo de aprendizagem e a importância de considerar as experiências cognitivas, estéticas, sociais, biológicas e afetivas dos alunos, justificando, assim, a proposição de ações pedagógicas que encaminhassem à flexibilização do tempo e do espaço.

A expressão "reorganização do tempo e espaço" surgiu como um eixo importante, para os educadores pesquisados, na organização do trabalho pedagógico e no repensar de um ensino para além das séries anuais, pois o principal referencial de que muitos deles dispunham no momento dizia respeito ao Ciclo Básico ${ }^{1}$ das escolas estaduais.

${ }^{1}$ Ciclo Básico: uma medida adotada por alguns estados, a partir de 1980 , na qual se reestruturavam as $1 .^{\text {as }}$ e $2 .^{\text {as }}$ séries em um continuum de dois anos. 


\section{O processo de pesquisa nas escolas organizadas em Ciclos de Aprendizagem}

A Rede Municipal de Ensino de Curitiba (RME) iniciou o processo de organização do ensino em ciclos, denominado Ciclos de Aprendizagem. No documento "A Escola Municipal e os Ciclos de Aprendizagem - Projeto de Implantação" (CURITIBA, 1999, p. 21), encontra-se a seguinte justificativa:

A implantação da organização escolar em ciclos de aprendizagem na RME é, portanto, a configuração da busca que também se faz pelo sucesso da escola pública, que pretende, mais do que a permanência do aluno na escola, a formação plena de todos os cidadãos.

A preocupação constante no aprimoramento da prática pedagógica fez com que muitos projetos fossem desenvolvidos nas temáticas de alfabetização, avaliação, planejamento e adequação idade-série, buscando uma proposta de ensino que tomasse como referência aprendizagens significativas, mudanças na postura profissional e valorização da cultura da comunidade.

As escolas que participaram da pesquisa estão localizadas na região sul da cidade de Curitiba, em comunidades diferenciadas sob o ponto de vista das condições socioeconômicas. Uma escola apresentou um quadro de profissionais que está há mais tempo na unidade e também no magistério municipal, e a outra apresentou um quadro relativamente novo de profissionais, tanto na escola como na RME. As duas escolas participaram desde o início do processo de implantação dos ciclos.

$\mathrm{Na}$ pesquisa as escolas foram identificadas como Escola Municipal Alfa e Escola Municipal Beta. As professoras da Escola Municipal Alfa receberam a denominação Prof. A1, Prof. A2, Prof. A3, Prof. A4 e Prof. A5, e as pedagogas, Ped. A1 e Ped. A2. As professoras da Escola Municipal Beta foram identificadas como Prof. B1 e Prof. B2, e as pedagogas, Ped. B1 e Ped. B2.

\section{Os dados da pesquisa}

Os elementos tempo/ espaço estão estabelecidos na escola há muitos anos, refletindo-se na organização das séries, nos níveis de aprendizado dos alunos, recuperações, aprovações, reprovações. 
Foi solicitado às professoras das Escolas Municipais Alfa e Beta que relatassem se, em função do processo de aprendizagem dos alunos, propuseram alguma forma de organização levando em consideração tempo/ espaço. Todas as professoras entrevistadas responderam afirmativamente e relataram as seguintes práticas:

Os alunos divididos em grupos de acordo com as dificuldades de aprendizagem. Em alguns casos deu resultado sim, quando o problema está no seu tempo/ espaço, como imaturidade, falta de recursos em casa, onde a criança só pode contar com o apoio do professor (Prof. A1).

Reorganização espaço-temporal: onde os alunos são divididos em grupos de acordo com as necessidades de aprendizagem. Organizei grupos menores de trabalho, por dificuldades, e a realização de atividades individualizadas e diversificadas com os alunos proporcionou a interação entre os alunos em diferentes niveis de aprendizagem (Prof. A2).

Respeitando o tempo do aluno, retomando o que foi ensinado, quando este não consegue dominar (Prof. A4).

Manter sempre uma rotina diária na sala, para que cada criança mantenha sua ansiedade em baixa (Prof. A5).

Com a outra professora, em outra sala. A ideia era agrupar alunos com dificuldades parecidas, num determinado dia da semana, para realizar um trabalho mais dirigido (Prof. B1).

Com atividades e encaminhamentos diferenciados em sala de aula. Também no horário de informática, onde a turma é dividida para trabalhar com as necessidades especificas (Prof. B2).

Verifica-se que, diante da diversidade no processo de aprender, algumas ações foram sendo implementadas, como é o caso da chamada reorganização de tempo/espaço ou espaço-tempo. Apesar do título, a essência desses reagrupamentos ainda não atingiu sua maturidade, como é possível observar nas falas das professoras B1, B2, A1 e A2.

$\mathrm{Na}$ fala das quatro professoras citadas, a organização de grupos diferenciados de alunos ocorre em função das dificuldades que são detectadas e, como afirma Meirieu (2005, p. 124), a formação dos grupos baseia-se num diagnóstico ainda hipotético, amparado pelas necessidades que se apresentam mais aparentes. As professoras, de maneira geral, passaram anos de sua formação preocupadas em articular ações didáticas para "ensinar tudo a todos na totalidade", ao mesmo tempo e no mesmo espaço. Caso alguns estudantes não conseguissem alcançar os saberes mínimos, permaneciam naquela série. 
Os conteúdos da docência, transmitidos ao longo da formação, transformaram-se no saber funcional do professor, como foi possível observar em algumas colocações das professoras, como, por exemplo, retomar o que foi ensinado, manter a rotina na sala de aula. Como salienta Arroyo (2000, p. 74), "a docência repetitiva de saberes fechados não estimula a pesquisa, nem a leitura e o embate, e torna-se um dos processos mais desqualificadores".

Essa docência "fechada" precisa ser rompida em nossas escolas, respeitando as memórias, experiências e caminhos trilhados pelos educadores, como coloca Moll (2004), porém desestabilizando toda uma rede de relações que ainda compromete a organização diferenciada dos horários, da organização das turmas, do planejamento, da proposição de trabalhos diferenciados.

Há urgência em reencontrar e reencantar as atividades docentes, para que não sejam apenas cópias de livros didáticos, ou a organização da sala de aula, formação de fileiras de alunos (digamos, os chamados fortes, fracos, médios, mal comportados).

Nas palavras de Moll (2004, p. 105),

trata-se de, a partir de processos de reflexão e ação constituídos há muito em muitas escolas, avançar na qualificação do espaço escolar como espaço de vida, como espaço de conhecimentos e valores, como espaço no qual a vida transita em sua complexidade e inteireza, como espaço no qual cada aluno e aluna, com razão e emoção, possa conhecer e operar com a música, com as ciências, com as artes cênicas, com as matemáticas, com a literatura... onde cada um e todos em relação possam humanizar-se e singularizarse, entendendo o mundo e entendendo-se no mundo.

As ações que envolvem arranjos de tempo/espaço não podem se constituir em ações isoladas de alguns professores. São organizações de grupos que ocupam determinados espaços na escola e, quando possível, fora dela, e que se reúnem porque são capazes de aprender.

A respeito dessas práticas citadas de reorganização dos grupos, Meirieu (2005, p. 125) esclarece que se trata de "ajuda temporária" e não formas definitivas de atendimento aos alunos. As escolas não podem esquecer que é na convivência e nas trocas estabelecidas a partir das diferenças que a aprendizagem organiza-se, transformando-se em desenvolvimento mental. 
Durante a entrevista realizada com a professora B2, ela forneceu dados de uma prática realizada com outra colega, que envolveu não somente seu grupo de alunos, mas uma parceria:

No ano passado eu e a professora $C$, que estava na segunda etapa, trocávamos alguns alunos. Eu sabia que o aluno $\mathrm{R}$ tinha problemas na multiplicação, então quando en ia trabalhar com uma atividade que envolvia multiplicação en ia "roubar" ele, para ficar na minha turma, para trabalhar com aquela atividade. E alunos meus iam para ela em determinados dias para trabalhar producão de textos. Eu entendo assim: se eu tenho um aluno na primeira etapa que esteja indo superbem, ele poderia estar lá na segunda etap a fazendo outras atividades (Prof. B2).

É possível alterar a palavra "roubar", utilizada pela professora por outra, como "troca". Excluindo a etapa do ciclo, que segmenta todo o processo, as professoras organizavam seus alunos com possibilidades de que "o mesmo e o outro se entrelacem no dia-a-dia na sala de aula e no estabelecimento [...]” (MEIRIEU, 2005, p. 127).

Os procedimentos que as professoras utilizam para integrar os elementos tempo/espaço necessitam embasar-se nas seguintes colocações de Meirieu (2005, p. 127):

sou como você porque necessito, como você, compreender tal questão do programa de história; sou como você porque adquiri com você as competências lingüísticas que nos permitem discutir a esse respeito. Mas sou diferente de você porque estudei um documento que você não conhece, porque lhe proporciono minha análise e minha sensibilidade, porque reciprocamente, posso questioná-lo sobre algo que você, por sua vez, sabe melhor que eu, e assim poderemos aprender juntos. Amanhã nesta hora, estarei em um grupo com outros alunos que, como eu, necessitam rever esta ou aquela questão de gramática. [...]. Desse modo, a história que construiremos será o resultado daquilo que faremos juntos com nossas respectivas contribuições [...].

Somos diferentes e, em alguns momentos, aprendemos com as diferenças e, em outros, com as possíveis semelhanças. Mas ainda observa-se que, em geral, a busca é pela turma homogênea, na qual todos aprendem ao mesmo tempo. 
$\mathrm{Na}$ entrevista com as pedagogas, foi solicitado que relatassem as ações didáticas que a escola desenvolvia para integrar os elementos tempo/ espaço na proposta de organização do ensino em ciclos. A elaboração dessa questão justifica-se por acreditar que ações de reorganização no ciclo envolvem todo o coletivo de professores, contando com a orientação da pedagoga, que pode articular diferentes estratégias, visando à melhoria das aprendizagens dos alunos.

A resposta obtida na escola Alfa, pela Ped. A1, foi: “em 2006, as ações se tornaram complicadas por haver adaptação da nova direção e rotatividade de profissionais". As mudanças na gestão administrativa das escolas, ao que parece, provocam descontinuidade de ações tanto de caráter pedagógico quanto administrativo. Aqueles que possuem funções administrativas precisam estar envolvidos sobre como os procedimentos didáticos utilizados correspondem ao projeto educativo da escola que assumem enquanto diretores.

Lima (2000, p. 20) adverte com propriedade: "a gerência da unidade escolar deve servir primeiramente à ação educativa, ou seja, ela deve ter como prioridade a concretização das ações necessárias para o desenvolvimento humano e todas as aprendizagens que os alunos necessitam realizar".

$\mathrm{Na}$ Escola Municipal Beta, as pedagogas não se remeteram à gestão, mesmo ocorrendo processo de eleição de diretores, como na outra escola. Nessa instituição, ficou visível a relação da direção com os assuntos pedagógicos e, sobretudo, uma continuidade dos processos já instaurados em anos anteriores:

Organizamos o contraturno, corregência, projeto de ciências (Ped. B1). Reorganização da avaliação escolar; substituir notas porpareceres descritivos, ampliação dos periodos bimestrais para semestrais, corregente, plano de apoio pedagógico (Ped. B2).

Em relação ao espaço físico da sala de aula, foi questionado como as professoras organizavam esse espaço, assim como quais os outros espaços que utilizavam para o desenvolvimento das atividades. De maneira geral, ficou constatado que a sala de aula é o espaço privilegiado para a organização das atividades diferenciadas para os grupos de alunos. Quanto à disposição física das carteiras, os arranjos são em fileiras ou duplas de alunos, mas sempre em fileiras.

A sala de aula apresenta uma linguagem significativa dos atores que dão vida a esta construção. Como citado nos estudos de Richardson 
(1997, p. 29), a maneira com que esse espaço é organizado influencia o diálogo, a comunicação entre alunos e professor, alunos e alunos, além de produzir efeitos emocionais importantes que influenciam na aprendizagem.

A sala de aula também funciona para a educabilidade de corpos, ideia incorporada à pedagogia pela psicologia e psicanálise do século XIX, em que corpo e mente se separam e aprender é manter uma rigidez dos movimentos.

Esse espaço já passou pelo seu momento de homogeneização, quando diversos testes foram aplicados nos alunos para organizar as classes de acordo com os aspectos físicos e mentais destes.

Como Veiga (2003, p. 94) informa,

o processo de homogeneização das salas de aula teve como objetivo agrupar as crianças de acordo com seu nível de inteligência, de aptidões e habilidades, de forma a possibilitar uma pedagogia adequada às características de cada grupo e racionalizar os esforços do professor.

A questão da utilização dos espaços nas escolas merece um planejamento com melhor definição, pois muitos são organizados para cumprir determinadas funções e assim permanecem, mesmo que as necessidades de alunos e professores sejam outras.

$\mathrm{Na}$ Escola Municipal Alfa, a Prof. A1 relatou: "a gente tem que ficar correndo atrás de outros espaços para ver se pode usar o espaço do pátio". Quando a professora planeja uma atividade para o grupo de alunos, diversos aspectos são considerados, com antecipação. Se o trabalho envolve a utilização de outro espaço físico, isso está previsto no planejamento, além da comunicação com demais professores, para evitar situações como esta descrita pela docente.

Em relação à utilização de outros espaços, duas professoras da escola Alfa contaram que utilizam o pátio coberto para atividades com jogos. As demais afirmaram que utilizam a sala de aula. Justificaram essa opção pela dificuldade de encontrar outro espaço disponível, pois a quadra é usada pela Educação Física. Elas não utilizam o laboratório de informática, pois não há professor de informática e alguns computadores encontram-se estragados.

$\mathrm{Na}$ Escola Municipal Beta, o laboratório de informática é utilizado como apoio às atividades e, em função das características dos alunos, os espaços externos são também utilizados: 
a gente utiliza o laboratório (de informática), mas cada turma tem o sen horário. E vai meia turma, tem dois horários por semana e conforme a semana eu organizo a turma de um jeito. Nesse momento eu trabalho com leitura na sala de aula e a professora de informática vai com metade da turma pra lá. Antes do dia das crianças, eu estava trabalhando jogos, brinquedos e brincadeiras, eu utiliz̧ei muito espaço. A gente via a instrução da brincadeira e ia lá fora brincar com eles. Eu tenho uma turma muito agitada. Eles não conseguem ficar o dia todo fazendo uma atividade só, sentadinhos. Eu preciso mudar muito com eles. Então eu vou lá para fora com eles (Prof. B2).

A outra professora da Escola Beta reafirma a utilização do laboratório de informática, mas já deixa claro que outro espaço (sala) seria necessário na escola.

Uma briga que nós temos aqui é para abrir uma salinha, de reforco, contraturno. A gente tem o laboratório de informática; por ser uma escola menor a gente tinha mais horários, dai a gente organizava a turma: alguns alunos iam para o laboratório, e aqueles outros eu trabalhava uma coisa específica (Prof. B1).

Quanto ao olhar das pedagogas sobre a organização do espaço em sala de aula, colocaram que, na maioria das vezes, a sala está organizada com uma carteira atrás da outra.

Em relação à utilização de outros espaços da escola, que são utilizados para o desenvolvimento das atividades, as pedagogas da Escola Municipal Beta informaram que as professoras procuram utilizar todos os espaços disponíveis: a sala de informática, o pátio, a cancha, atividades nas mesas da sala dos professores. Na Escola Municipal Alfa, o espaço é a sala de aula, relatam as pedagogas. A literatura consultada aponta para a questão do uso do espaço pelos educadores, a partir de uma organização mais disciplinadora, na qual possam exercer um monitoramento maior das ações dos alunos, pois a escola é herdeira das ideias de controle dos movimentos dos corpos para se obter o controle das mentes, e assim conseguir que meninos e meninas tenham um bom aprendizado.

Segundo Horn (2004, p. 28), “a arquitetura escolar [...] materializa todo um esquema de valores, de crenças, bem como os marcos da atividade sensorial e motora". Então, desde a construção dos edifícios escolares, já se encontram as marcas que encaminham para determinada forma de 
organização do espaço, em torno da figura do professor, uma vez que é ele quem ensina e o aluno é quem aprende.

É necessário que o espaço da escola seja trabalhado como um cenário que se constitui a partir das relações humanas que ali se estabelecem, os elementos simbólicos que se fazem presentes, a organização e distribuição de matérias que proporcionem aos alunos o desenvolvimento de diversas habilidades, que possam instigar a curiosidade infantil.

Se as construções escolares nos últimos anos passaram de projetos arquitetônicos padronizados para edificações diferenciadas, inovadoras, que atendem às necessidades dos educandos e dos educadores, os docentes devem estar preparados para utilizar os espaços das escolas com maior inventividade e flexibilidade.

\section{Considerações finais}

Mudar a organização do ensino em séries, cujos pressupostos pautam-se na adequação do processo de aprendizagem e de docência a um período de tempo rígido e um espaço demarcado trata-se de reconstruir com os professores os tempos/espaços culturalmente instituídos e os tempos/ espaços de desenvolvimento e de aprendizagem, para que progressivamente reflitam sobre o tempo/espaço no ensino organizado em ciclos.

Repensar o tempo/espaço na escola, em seu cotidiano, diz respeito a observar com atenção as diversas estruturas. É rever a importância destes elementos na organização do ambiente escolar, nas questões metodológicas, na organização dos grupos de trabalho dentro e fora das salas de aula, no planejamento, na interação entre alunos e alunos, entre professores e alunos, professores e professores.

Respeitar o tempo de aprender dos alunos na escola organizada em ciclos é lhes proporcionar acolhimento, questionamentos, embasamentos e diferentes possibilidades de expressão diante dos conteúdos acadêmicos.

Diz respeito à efetivação de planejamentos com os docentes, para que, além das citações sobre conteúdos e atividades, discutam-se questões relacionadas ao tempo/espaço pensados para o desenvolvimento das ações educacionais e como esses elementos estão relacionados às experiências proporcionadas no ambiente escolar e aos processos cognitivos dos sujeitos. 
No contexto escolar, é preciso considerar o que é instituído pelo tempo dos calendários e relógios, refletindo sobre o tempo que os alunos ocupam no desenvolvimento das atividades pedagógicas, quais espaços utilizam, visando a identificar os diferentes estilos de aprendizagem e, consequentemente, diferentes estilos de ensinar.

Refletir sobre o tempo dos alunos revela a preocupação não somente com o cumprimento do rol de conteúdos, mas com a diversificação metodológica e com o processo de aprendizagem. O tempo na organização do ensino em ciclos é uma questão de respeito às diferenças individuais, que demanda uma análise e mudança de atitude relacionada às representações sobre o aluno, infância, sobre o papel da docência e o significado da diversidade em sala de aula.

Não se trata de utilizar este elemento para configurar situações de aprendizagem conformistas, ou seja, apenas dizer que a criança necessita de mais tempo para aprender, sem que alterações significativas sejam realizadas na prática dos professores e nas atividades do cotidiano escolar.

Desenvolver uma prática docente na escola organizada em ciclos corresponde a pensar a organização do tempo/espaço na medida em que favoreçam a socialização, promovam o trabalho de equipe, planos de trabalho que enfatizem aprendizagens significativas e que possam estar adequados à diversidade do processo de aprender.

A questão do tempo institucional apresenta-se fortemente marcada na estruturação dos calendários escolares, organização dos horários para os alunos, na tarefa de ministrar os conteúdos relacionados para uma determinada série - mesmo com as Diretrizes Curriculares para a Educação Municipal de Curitiba apresentando objetivos, conteúdos e critérios de avaliação, de acordo com a organização em ciclos. ${ }^{2}$

Os agrupamentos em sala acontecem de dois em dois alunos, ou grupos de quatro alunos, que são atendidos pela professora regente de turma ou pela professora corregente, na sala de aula, ou fora dela. São reorganizações em função de uma dada dificuldade que os alunos apresentam em um determinado momento, constituído procedimentos pontuais.

Observou-se que em termos da organização no espaço da sala de aula, esta não pode manter a padronização das filas individuais, e nem ser um casulo; ela é um espaço de movimento.

\footnotetext{
${ }^{2}$ As Diretrizes Curriculares para a Educação Municipal de Curitiba foram estruturadas no período de 2005 e 2006, sendo que anteriormente dois documentos já haviam sido organizados: Diretrizes Curriculares em Discussão (2001) e Diretrizes Curriculares - o currículo em construção (2004).
}

Rev. Diálogo Educ., Curitiba, v. 10, n. 31, p. 679-692, set./dez. 2010 
Também se evidenciou que outros espaços precisam receber maior atenção nas discussões pedagógicas, pois ganham significados a partir dos usos atribuídos a eles pelos professores e alunos nas tarefas realizadas.

As professoras destacaram algumas práticas, como o trabalho paralelo com o laboratório de informática e reorganizar agrupamentos de alunos ou mesmo de apenas um aluno, dadas as necessidades no processo de aprendizagem que são apresentadas, bem como as possibilidades de os alunos participarem de uma etapa, realizando atividades com alunos que se encontram em outro ano do mesmo ciclo, pois apresentam nível de aprendizagem e desenvolvimento. Porém, esse último tipo de reorganização foi levantado por apenas uma professora, na Escola Municipal Beta.

Considera-se que os elementos tempo/espaço na escola organizada em ciclos estão inseridos na prática cotidiana dos professores relacionados ao cumprimento de horas e dias letivos e também ao tempo dos conteúdos e pré-requisitos para a etapa seguinte.

Análises de maneira continuada precisam ser realizadas, para que o Ciclo de Aprendizagem não se constitua em desenvolvimento por etapas, mas no conjunto do tempo/espaço do ciclo, objetivando a formação integral dos alunos.

\section{Referências}

ARROYO, M. G. Oficio de mestre: imagens e auto-imagens. Petrópolis: Vozes, 2000.

CURITIBA. Secretaria Municipal da Educação -SME. Proposta de Implantação dos Ciclos de Aprendizagem na Rede Municipal de Ensino de Curitiba. Curitiba: SME, 1999.

HORN, M. da G. S. Sabores, cores, sons, aromas: a organização dos espaços na educação infantil. Porto Alegre: Artmed, 2004.

LIMA, E. S. Ciclos de formação: uma reorganização do tempo escolar. São Paulo: Sobradinho, 2000.

MEIRIEU, P. O cotidiano da escola e da sala de aula: o fazer e o compreender. Porto Alegre: Artmed, 2005. 
MOLL, J. Ciclos na escola, tempos na vida: criando possibilidades. Porto Alegre: Artmed, 2004.

RICHARDSON, V. Espaço e tempo. In: ARENDS, Richard I. Aprender a ensinar. 1997. Disponível em: <http://www.dgidc.min-edu.pt/DEB/recursos/ biblioteca_digital/biblioteca_digital.asp>. Acesso em: 13 jan. 2006.

VEIGA, C. G. Lições da pedra: a sala de aula e a produção do aluno. In: VIELLA, Maria dos Anjos Lopes. Tempo e espaço de formação. Chapecó: Argos, 2003. p. 49-102.

Recebido: $16 / 04 / 2010$

Received: 04/16/2010

Aprovado: $21 / 06 / 2010$

Approved: 06/21/2010 